\title{
European Journal of General Practice
}

\section{Faculty development for teachers of family medicine in Europe: Reflections on 16 years' experience with the international Bled course}

\section{Mateja Bulc, Igor Švab, Smiljka Radić, Jaime Correia de Sousa \& John Yaphe}

To cite this article: Mateja Bulc, Igor Švab, Smiljka Radić, Jaime Correia de Sousa \& John Yaphe (2009) Faculty development for teachers of family medicine in Europe: Reflections on 16 years' experience with the international Bled course, European Journal of General Practice, 15:2, 69-73, DOI: $10.1080 / 13814780903071930$

To link to this article: http://dx.doi.org/10.1080/13814780903071930

进 Published online: 18 Jan 2010.

Submit your article to this journal $₫$

山 Article views: 55

Q View related articles $\sqsubset$

Citing articles: 4 View citing articles 4 


\title{
Faculty development for teachers of family medicine in Europe: Reflections on 16 years' experience with the international Bled course
}

\author{
MATEJA BULC ${ }^{1,2}$, IGOR ŠVAB ${ }^{2}$, SMILJKA RADIĆ ${ }^{3}$, JAIME CORREIA DE SOUSA ${ }^{4}$ \\ \& JOHN YAPHE ${ }^{4,5}$
}

${ }^{1}$ Community Health Centre Ljubljana, Ljubljana, Slovenia, ${ }^{2}$ Department of Family Medicine, Ljubljana University School of Medicine, Ljubljana, Slovenia, ${ }^{3}$ Medicinski fakultet, Beograd, Serbia, ${ }^{4}$ Department of Community Health, School of Health Sciences, University of Minho, Braga, Portugal, and ${ }^{5}$ Department of Family Medicine, Sackler Faculty of Medicine, Tel Aviv University, Tel Aviv, Israel

\begin{abstract}
Background: Instruction in principles and methods of medical education is a core component of the training of medical teachers. Curricula for new medical teachers have developed across Europe, but few European courses have had the success of the EURACT Bled course for teachers of family medicine. The course focuses on practical issues in medicine and the professional development of physicians. This article describes 16 years' experience with the Bled course for teachers in general practice/family medicine (GP/FM). Course structure: The course is centred on the preparation of a teaching module, exploring a specific theme in family medicine. The main teaching methods used are: keynote lectures, small group sessions, field work and preparation of a teaching module by the participants. Outcomes: This course has attracted 555 participants from 20 countries since 1992. The course and its outputs have been applied in undergraduate and postgraduate teaching, and in continuous professional development (CPD) in several countries. It is a respected forum for faculty development. The experience of the Bled course suggests that academic medicine may be better able to fulfil its responsibilities by paying attention to relevant topics and using appropriate methods in undergraduate and postgraduate medical curricula.
\end{abstract}

Key words: family medicine, teacher training, faculty development, continuing medical education, continuous professional development, Slovenia

\section{Introduction}

Acquiring knowledge and technical skills is the main objective of medical education, but this alone is not sufficient for the practice of medicine. Enabling medical students and vocational trainees to become skilled and independent decision makers dedicated to the well-being of their patients is another central task of medical education and a core skill of medical teachers (1).

The academic speciality of family medicine is developing rapidly in all European countries, because of the increasing needs of patients, and the recognition by secondary and tertiary care physicians and politicians that well-trained family doctors can meet many of these needs efficiently. Family physicians need to be trained to meet both professional standards and public and political expectations.

Slovenia has a long tradition of speciality training in family medicine (2). It became obvious early in the development of the academic speciality that a course of faculty development would be necessary to train the teachers who would train competent future family doctors. The international Bled course for teachers in family medicine began in 1991 as a response to the needs of Slovenian trainers to adopt modern developments in the teaching of family medicine. Prior to 1991, Slovenian teachers participated in a course run by the Inter-University Centre in Dubrovnik. During the years of the war in

Correspondence: Mateja Bulc, Karlovška 7, SI-1000 Ljubljana, Slovenia. Tel: +386 41239243. Fax: +386 15053542. E-mail: mateja.bulc@email.si 
Croatia, the course stopped. At that time, a new course developed in Slovenia.

Since 1992, the Bled course has acquired a reputation as a popular international training forum for teachers and trainers in undergraduate and postgraduate medical education. The directors of the Bled course recognized that effective preparation of trainers requires attention to topics specific to family medicine, the use of different methods for acquiring knowledge and skills, attention to the level of professional development of the trainee, and orientation to dilemmas experienced in everyday practice. In recognition of its quality, it became one of the official courses of the European Academy of Teachers in General Practice (EURACT) (3). EURACT enabled many participants to attend the course through a scholarship programme.

\section{Course content}

The field of family medicine is complex. This complexity is described in the European definition of family medicine. Because family medicine is a broad field, the teaching of family medicine is also complex and needs to cover themes that are often not covered by traditional medical curricula (1).

The aims of the Bled courses were to cover topics that are of particular importance to family medicine. The list of course topics also reflects the philosophy of family medicine, described in the European definition. Topics have covered organizational issues and clinical care, medical record keeping, prescribing, doctor-patient communication, prevention, management of chronic disease, involvement of families, evidence-based medicine, emergencies and out-ofhours services, quality assurance, medical errors and ethical dilemmas, community orientation, patientcentred clinical care in modern cross-cultural communities, co-morbidity, and patient empowerment (Table I).

\section{Teaching and learning methods}

In keeping with the novelty of the subject matter, new teaching methods have been employed in the course. Prior to the course, selected background material is made available on the website of the Slovene Family Medicine Society along with an assignment to be completed in advance (3). The course lasts for 5 days. Several teaching methods are used, including sharing of clinical experiences in small-group discussions, lectures, workshops, panel discussions, problem-based learning exercises, roleplaying, and small-group tutorials. These methods encourage active learning instead of passive listening. The use of various teaching methods employed by an international team of educators allows the course to adapt to individual differences among the participants and to "teach the participant as a person" (4). This preparatory work leads up to the preparation of teaching modules on the selected course topic. Each working group is invited to select a more focused theme from the broader course topic and to develop a teaching module that is considered appropriate for application by the group members in their work setting.

Each day of the course starts with an opening plenary session in the form of a keynote lecture on one aspect of the selected topic, which is intended to inform and stimulate the discussion in small-group sessions that follow the lecture. Small-group work is an essential part of the course. Groups are limited in

Table I. List of Bled course topics.

\begin{tabular}{lrl}
\hline Location & \multicolumn{1}{c}{ Date } & Topic \\
\hline Bovec & $8-10.10 .1992$ & Practice organisation \\
Bovec & $30.9--3.10 .1993$ & Medical record keeping \\
Gozd Martuljek & $6-10.9 .1994$ & Quality assurance \\
Gozd Martuljek & $5-9.9 .1995$ & Doctor-patient communication \\
Bled & $3-7.9 .1996$ & Prevention \\
Bled & $2-6.9 .1997$ & The family \\
Bled & $8-12.9 .1998$ & Prescribing \\
Bled & $7-11.9 .1999$ & Management of chronic diseases \\
Bled & $5-9.9 .2000$ & Evidence-based medicine \\
Bled & $4-8.9 .2001$ & Medical errors \\
Bled & $3-7.9 .2002$ & Out-of-office medicine \\
Bled & $2-6.9 .2003$ & Ethical problems \\
Kranjska Gora & $7-11.9 .2004$ & Patient-centred care in modern \\
Kranjska Gora & & cross-cultural communities \\
Bled & $20-24.9 .2005$ & Co-morbidity \\
Bled & $19-23.9 .2006$ & Community orientation \\
\hline
\end{tabular}


size to 12 participants. This enables participants from various countries to present their personal and national experiences, obstacles, and achievements, to discuss problems, and to feel a part of the "family medicine family". Each group is facilitated by one of the course directors. Facilitators have several tasks: introducing participants to each other, eliciting national experiences on the course topic, encouraging presentation of "homework", stimulating discussion on the ideas presented in keynote lectures, and helping with preparation of the teaching module. Facilitators enable all participants to express themselves, and nominate a reporter for each session to report on small-group discussions to the plenary.

Fieldwork is a very popular element of the course. Local family physicians enable participants to make a home visit, accompanied by local practice nurses, to patients with health problems related to the course topic. At the home visit, participants fieldtest the hypotheses prepared in the small-group sessions. After the home visits, the small groups gather in the local health centre and report on their experiences to the other course participants and to local family physicians.

Presentation of teaching modules takes place on the last day of the course at the final plenary session. Each working group chooses a teaching topic, related to the subject of the course, selects a target audience (students, trainees, or family physicians), and chooses relevant teaching methods and tools for the evaluation of the proposed course. Courses are designed to be applied in different countries. Participants expend considerable energy in preparing and polishing their modules to make an attractive presentation on the final day. The course ends with the collection of oral and written feedback from the participants on the course topic, small-group work, fieldwork, and the performance of the course directors.

Course feedback has played an important role in the ongoing assessment and improvement of the course. The course directors meet after the conclusion of the course to review the feedback to suggest strategies for improvement and to begin preparations for the following year. In recent years, most course preparation has been done by communication between course directors via electronic mail and Internet telephone.

The core group of course directors has been stable for the past 16 years. In addition, course directors who are content experts in certain course topics have sometimes been invited to participate.

In order to assess the impact of the course, participants were asked to describe the effects of the course in their own countries. We were specifically interested in whether courses on the same topics were organized locally. We have also gathered information about the number of participants from reports on previous courses. Participants were asked how the course was integrated into existing curricula in medical schools and how the course topics were applied to learners in vocational training and CME.

\section{Results}

Since 1992, 555 participants from more than 20 countries from Europe, Turkey, New Zealand, and Israel have attended the international Bled course for family physicians. Reports on the integration of course materials in undergraduate and postgraduate medical education were received from the following countries: Slovenia, Serbia, Israel, Portugal, and Austria.

\section{Slovenia}

Since 1992, a series of workshops on the same topics as the Bled course have been organized following the course for Slovenian teachers of family medicine. The workshops are shorter in duration, but provide the material covered by the courses in a more concentrated way. Teaching materials are provided in Slovenian (2), and the course is organized by the Slovenian participants who attended the international course. These courses are a prerequisite for recognition as a tutor of family medicine. This requirement has been accepted by both medical schools in the country. One hundred and thirty Slovene family physicians have been trained by the international course and the local versions of the course.

\section{Serbia}

Since 2002, Serbia has been successful in adapting the Bled course locally. More than 10 national courses have been prepared. After the first two Serbian general practitioners participated in the Bled course in 2002 on "Learning and Teaching about Medical Errors in General Practice", they shared their experience with other Serbian general practitioners at a conference held in Vrnjačka Banja the same year.

One-day courses followed in 2003 at the Belgrade University School of Medicine on medical errors, ethical issues, and patient centeredness in modern cross-cultural communities. One-day courses on the same topics were organized for Serbian trainees in general practice in May and June 2005, by two Serbian and two Slovene teachers. These topics were eventually incorporated into specialist training in 
general practice at the School of Medicine of the University of Belgrade.

In April 2007, a two-day course organized by the Serbian Medical Society, General Practice Section, was held in Palic, on "Learning and Teaching about Community Orientation in General/Family Practice". It was presented by three Serbian teachers who were Bled course participants. Fourteen physicians from Serbia applied for the Bled course in September 2007.

In April 2008, another course for general practice trainers was held in Zlatibor, organized in collaboration with the Serbian Medical Society, General Practice Section, with Serbian Bled course participants and Slovene teachers, under the patronage of EURACT.

\section{Israel}

In Israel, Bled course materials have been used in many different settings. In 2005, several seminars on medical anthropology for general practice teachers were held in different locations in Israel. The academic medicine course of faculty development for teachers of family medicine at Tel Aviv University in 2006 used material from the 2004 Bled course on cross-cultural medicine. This material was also presented as an international workshop at the 2005 WONCA conference in Kos. Material from the 2003 Bled course on medical ethics was used in the faculty development course for teachers of family medicine at Tel Aviv University in 2004 and 2006, and was presented to general practice teachers in Ireland (2004), Israel (2005), and Portugal (2007). Material from the 2001 Bled course on medical errors was presented at workshops to general practice teachers in Israel (2003), Ireland (2004), and Portugal (2007). The workshop on breaking bad news from the 2001 course was presented at the WONCA Europe international conference in 2005 in Kos. The material on family assessment (from the 2002 course on out-of-hours work) has been used in Israel annually since then for students, residents, and general practitioners (GPs).

\section{Portugal}

Adaptation of material from Bled courses to teaching settings in northern Portugal began in 1993; the vocational training scheme and CME activities were the first areas in which the experience from Slovenia was successfully used. Later on, sessions in the family medicine undergraduate programme and clerkships in the medical school of Minho University (School of Health Sciences) served as the foundation for extended use of the learning and teaching methods, course references, teaching modules, and tools from Bled, including the following interesting examples. The course material on prevention and on the family was used for the vocational training scheme and inspired a model for a course in the "Bled style", which lasted for a number of years in CME activities. The course materials on prescribing and on the management of chronic diseases were used in the vocational training programme, in CME activities, in family medicine undergraduate teaching, and in a Master's course in Health Sociology. The course material on out-ofoffice medicine was also used in CME activities, in family medicine teaching and clerkships, and guest lectures in postgraduate programmes. The course materials on ethical problems, patient-centred clinical care, and co-morbidity were used for CME activities, for sessions in the medical school family medicine clerkships, and for postgraduate studies/ Master's programme in Health Sociology. The course material on community orientation was used for CME activities and a Master's programme in Health Sociology. The course material on patient empowerment was used not only for CME activities and for sessions in the family medicine clerkship, but also for postgraduate studies. Course materials on patient-centred clinical care, co-morbidity, community orientation, and patient empowerment inspired several editorials in the Portuguese Journal of General Practice (5-9).

The Bled courses exerted a distant but steady attraction on Portuguese family medicine teachers, though for most, attendance always met with financial or calendar difficulties; for a few of them, it was recently possible to become part of the "Bled Family" and start attending the course more regularly. For those, the Bled experience is always regarded as a turning point in their activity as teachers and family physicians, and they all look forward to another chance to return once more to the supportive learning and teaching environment.

\section{Austria}

In Austria, there is a yearly report on the Bled course in lecture format to teachers from all teaching practices, but no comparable courses have been organized so far.

No information was obtained on the application of Bled course teaching materials and methods in Hungary, Croatia, Estonia, Turkey, the UK, Ireland, and Italy. 


\section{Discussion}

Teaching family medicine to medical students, vocational trainees, and colleagues requires a broad professional outlook. An international perspective enables the teacher to maintain a wide view, focusing on core concepts without getting bogged down in local issues and obstacles. The international Bled course for teachers of family medicine has been successful in promoting this view. The choice of topics relevant to the daily practice of family doctors coupled with a varied international audience and teaching staff have served this aim. The use of innovative teaching methods has promoted active adult learning. The spread of ideas from the Bled course through replication of course materials in many different settings and countries is evidence of its applicability and relevance.

The future of the Bled course appears promising. There remains a need for an international forum for the teaching of family medicine in Europe in order to exchange ideas and to learn new concepts and teaching methods. It is hoped that the European Academy of Teachers in General Practice and the Slovene Society of Family Physicians will continue to support this worthwhile educational activity for the benefit of general practice teachers in Europe.

\section{References}

1. Allen J, Rashid A. What determines competence within a general practice consultation? Assessment of consultation skills using simulated surgeries. Br J Gen Pract 1998;48:1259-62.

2. Bulc M, Švab I, Rotar Pavlič D, Kolšek M. Specialist training of Slovene family physicians. Eur J Gen Pract 2006;12:128-32.

3. Švab I, Yaphe Y, Correia de Sousa J, Passerini G. An international course for faculty development in family medicine: the Slovenian model. Med Educ 1999;33:780-1.

4. Wilson MA, Blondefield PJ. Teaching "doctoring": a model curriculum for family medicine. JAOA 2007;107:30-4.

5. Sousa JC. Ups! Is it MUPS? Rev Port Clin Geral 2006;22: 277-9.

6. Sousa JC. The community orientation of family medicine. A matter of wisdom. Rev Port Clin Geral 2006;22:417-20.

7. Sousa JC. Chronic diseases and the challenges of co-morbidity. Rev Port Clin Geral 2005;21:533-4.

8. Sousa JC. The fish and the fishing rod. Notes on empowerment, enablement and health care. Rev Port Clin Geral 2007; 23:353-8.

9. Yaphe J. Teaching and learning about empowerment in family medicine. Rev Port Clin Geral 2007;23:365-7. 